\title{
Mental Health Literacy Among Youth in Surakarta
}

\author{
Setia Asyanti and Usmi Karyani \\ Muhammadiyah University of Surakarta \\ setia.asyanti@ums.ac.id
}

\begin{abstract}
Having an adequate knowledge of mental disorders is valuable for recognizing, preventing and treating them effectively This study explored the adolescence's general knowledge of mental disorders (mental health literacy) in Surakarta, Indonesia. Dat: was collected by an open ended questionaire developed from Jorm's theory of mental health literacy. There were 130 students fron 5 junior dan senior high schools in Surakarta who participated in this study. Descriptive analysis was taken to all data. Results showed that students's mental health literacy were not adequate. Their knowledge about mental disorder were not comprehensive Behavioral symptoms of mental disorders were easier to be recognized than emotional and cognitive symptoms. They stated tha stress, lack of self confident, lack of problems solving skill as mental disorders than psychological problems. The students only knew single factor that was responsible for mental disorders. Some of them knew the proper prevention and early intervention for peopls with mental disorders, but some did not know. Consequently, the mental health literacy course is needed forthe students to increase their skill to recognize simptoms of mental disorders and to support them with an adequate prevention dan early intervention.
\end{abstract}

Keywords :Mental health literacy, mental health signs, early intervention.

\section{INTRODUCTION}

Mental disorders often arrise for the first time in adolescents or young adult. If they are recognized and treated early, this may increased the chances of a better long term outcome (Jorm, Korten, Jacomb et all,1997). The rate of mental disorders of youth has been estimated to be between 20-27 \% (Burn \& Rapee,2005). Approximately one in five young Canadians may experience a mental disorder requiring professional care (Kesler, Berglund, Demler et all, 2005). The prevalence of common mental helath disorders indeveloping countries has been reported to be at least as common as in developed countries (Kicbusch, 2001). Prevalence of mental disorder in Indonesia was 1.7 per mil. Most of severe mental disorders could be found in 5 province. Those were Special region of Yogyakarta, Aceh, South Sulawesi, Bali and Central Java (National Health Research, 2013). But, this was the rate of general population and no intended especially for adolescents.

Jorm et all (1997) defined mental health literacy as knowledge and belief about mental disorders which aid their recognition, management or prevention. Mental health literacy consist of several components, including : (1) the ability to recognize specific disorders or diffrerent types of psychological distress (2) knowledge and belief about risk factors and causes, (3) knowledge and belief about self-help intervention, (4) knowledge and belief about professional help available, (5) attitudes which facilitate recognition and appropriate help-seeking, (6) knowledge of how to seek mental health information.

The mental health literacy of adolescents and young adults is not high. Previous research indicates that less than $50 \%$ of young people aged $12-25$ years are able to identify depression correctly and only about a quarter are able to identify psychosis (Wright, Harris, Wiggers, et all 2005). Bathia (2007) added that unrecognize and/or untreated mental disorders can lead to a variety negative outcomes including poor educational/vacationalachievement, problematic interpersonal and family functioning, and reduced life expectancy due to associated medical condition and suicide.

Study conducted by Lam (2014) found that mental health literacy was a potential factor that could have an impact on mental health status of adolescents. Enhancing the mental health literacy level should be considered as an important preventive measure of mental health problems of young people. Adequate level of mental health literacy is represented when both aspect are satisfied indicating that not only the individual acquire an understanding of problems, but also having a positive attitude toward help seeking action. Rickwood, Deane, Wilson and Ciarroci (2005) stated that insufficient knowledge to identify mental health symptoms and to access treatment impact on poor seek help action on adolescents.

In Jogjakarta, the special region in Indonesia, Oktavianus and Ramdahani (2012) found that mental health literacy through website and chatbot could increase adolescents' knowledge about depression. Website was more effective than chatbo.

Schools are an ideal venue in which to embed mental health literacy at both the individual and population level because schools are where most young people can be reached and classroom based education activities are familiar to the students and educators alike (Atkins, Hoagwood, et all 2010; Wyn, Cahill, Holds et all, 2000).

To our knowledge, the study conducted on mental health literacy in adolescents in Indonesia are still low. This study aims to explore the knowledge and belief of the adolescents about mental disorder.

\section{METHODS}

This study was an exploratory research utilising survey methode. Unit analysis in this study was knowledge about mental disorders or mental health literacy. Component of mental health literacy were (1) knowledge about mental disorders, (2) knowledge about simptoms of mental disorders, (3) belief about causes factors, (4) early intervention or helping behavior and (5) prevention.

This research conducted in Surakarta, one of city in Central Java Province in Indonesia in 2016. Total respondents were 130 students who came from 3 junior high schools and 2 senior high schools. All schools were choosen based on the permission from the headmaster.

Questionaire was used to collect data from the respondent which is developed based on the concept of mental health literacy from Jorm (1997). An open ended question were used to reveal 5 component of mental health literacy and was given to the adolescenes.

Response of the respondent in each question was categorized according to the thema, then analized by descriptive statictic. 


\section{RESULTS}

All of 130 students responded the questionaire completely. The characterictic of the respondents were summarized on table 1 .

Table 1 Frequency (\%) of the characteristics of study participants $(\mathrm{N}=116)$

\begin{tabular}{ccc}
\hline Characteristic & $\mathrm{n}$ & $\%$ \\
\hline Education : & & \\
Junior high school & 65 & 50,00 \\
Senior hign school & 65 & 50,00 \\
Sexe & & \\
Male & 56 & 43,08 \\
Female & 74 & 56,92 \\
\hline
\end{tabular}

As shown from table 1 , the number of students from junior high schools was the same as senior high schools. According to the sexe, the procentage of female $(56,92 \%)$ is higher than male $(43,08 \%)$.

The findings are described in order of item inthe mental health literacy questionaire. The first question asked the respondent's knowledge about mental disorders. The respondents were asked " According to your knowledge, what is called as the mental disorders ?" This open ended questions revealed a lot of responses from the respondents. The responses than coded as 6 category as shown in table 2 .

The majority of respondents could not answer the first question accurately. They only stated mental disorders as disorder in a single area of the individual, such as emotion (41,54\%), behavior (16,92\%), thinking process or cognition $(7,69 \%)$ and brain $(3,08)$. Frequency of respondents who have misunderstood that stress as a sample of mental disorder as much as $13,85 \%$. More over, unemployment, lack of confidence were stated as mental disorders by 16,92 $\%$ of the respondents.

Table 2. Frequency (\%) of response on knowledge of mental disorders

\begin{tabular}{lcc}
\hline \multicolumn{1}{c}{$\begin{array}{l}\text { Knowledge of mental } \\
\text { disorders }\end{array}$} & $\mathrm{N}$ & $\%$ \\
\hline $\begin{array}{l}\text { Problems with } \\
\text { emotion, } \\
\text { psychological } \\
\text { problems }\end{array}$ & 54 & 41,54 \\
$\begin{array}{l}\text { Problems related to } \\
\text { behavior }\end{array}$ & 22 & 16,92 \\
$\begin{array}{l}\text { Stress } \\
\begin{array}{l}\text { Problems on thinking } \\
\text { process or cognition }\end{array}\end{array}$ & 18 & 13,85 \\
$\begin{array}{l}\text { Problems in brain or } \\
\text { related to nervous } \\
\text { systems (fever, }\end{array}$ & 10 & 7,69 \\
$\begin{array}{l}\text { Others } \\
\text { unemployment, lack } \\
\text { of confedence, etc) }\end{array}$ & 4 & 3,08 \\
\hline \multicolumn{1}{c}{ Total } & 22 & 16,92 \\
\hline
\end{tabular}

The second question pertained to the causes of mental disorders. The respondents only stated one factor as the cause of mental disorders. Psychological stressors was called to be the main caused of mental disorders. It was stated by $63,85 \%$ of the respondents. They defined psychological problems as trauma, deep dispointment, frustration dan unable to cope with problems. The otherfactors were social $(11,54 \%)$, biological $(7,69 \%)$, economic $(5,38 \%)$ and religious $(2,31 \%)$ factors. There were $9,23 \%$ respondents who described some symptoms as the causes of mental disorders, such as never smile and daydreaming all the time. No one stated that many factors influenced mental disorders.

Table 3. Frequency (\%) response on causes of mental disorders

\begin{tabular}{lll}
\hline Causes & Sum & $\%$ \\
\hline psychological stressor & 83 & 63,85 \\
social stressor & 15 & 11,54 \\
Biologic factors & 10 & 7,69 \\
economic stressor & 7 & 5,38 \\
$\begin{array}{l}\text { Religious (lack of faith) } \\
\text { Others (never smile, day dreaming al }\end{array}$ & 12 & 2,31 \\
time etc) & 3 & 9,23 \\
\hline Total & 130 & 100 \\
\hline
\end{tabular}

Third, the participants were asked to describe symptoms of mental disorders. The majority of respondents $(68,46 \%)$ were readily to identify behavioral symptoms of mental disorders. They were unrealistic behavior, talking or laughing to his or herself, daydream all the day, etc. Respondents were less likely to identify the cognitive $(13,08 \%)$ and emotional $(7,69 \%)$ signs.An example of emotional symptoms were unstable emotion, madness, angry or anxiety without any reasonable reasons.

Table 4. Frequency (\%) of response on simptoms recognition

\begin{tabular}{lll}
\multicolumn{1}{c}{ Table 4. Frequency (\%) } & of response on simptoms recognition \\
\hline Simptoms & Sum & $\%$ \\
Cognavioral & 89 & 68,46 \\
Emotional & 17 & 13,08 \\
Others (genetic, sick etc) & 10 & 7,69 \\
\hline Total & 14 & 10,71 \\
\hline
\end{tabular}

The fourth question asked the respondents about their response to help people with mental disorders. Most of the respondents $(55,38 \%)$ knew that social support was the most important thing they could give to the person with mental disorders. Behaviors that represent social support were motivating, chatting, giving some advices and helping them to solve their problems. Family and Friends were stated as the most important sources of social support. The second action to help people with mental disorders was accompany them or their family to seek professional help. It was stated by $25,38 \%$ of the respondents. Only a few respondents $(3,85 \%)$ choosed religious activity. What should get our attention was there were still about $16 \%$ of students who lack of knowledge of helping behavior. One of the respondents choose "Pasung", means tighted the patients with rope and made them stayed in room or house all the day. The other answers that not relevan to the questions were sending them to the special schools, practising happiness all the day and trying to accept his or her self and another people. 
Table 5. Frequency (\%) of response on knowledge of Helping behavior

\begin{tabular}{lll}
\hline Helping berhavior & Sum & $\%$ \\
\hline Giving social support & 72 & 55,38 \\
seeking profesional help & 33 & 25,38 \\
religious activities (praying etc) & 5 & 3,85 \\
"pasung" & 1 & 0,77 \\
$\begin{array}{l}\text { Others (being happy, doing therapy, } \\
\text { tc) }\end{array}$ & 20 & 15,38 \\
\hline
\end{tabular}

Finaly, the last quesion revealed their knowledge of prevention for mental disorders.

Table 6. Frequency $(\%)$ of knowledge of prevention for mental disorders

\begin{tabular}{lll}
\hline How to prevent mental disorders & $\mathrm{N}$ & $\%$ \\
\hline Seeking for social support & 34 & 26,15 \\
Consult to psychologist, psychiatrist, doctor & 32 & 24,62 \\
Positive thinking & 23 & 17,69 \\
Increase religious activities & 13 & 10,00 \\
Self management & 11 & 8,46 \\
Recreation & 4 & 3,08 \\
To be patient & 3 & 2,31 \\
Don't know the answer & 8 & 6,15 \\
Engaging healthy life syle & 2 & 1,54 \\
\hline Total & 130 & 100 \\
\hline
\end{tabular}

Based on table 6, respondents described many efforts could be choosed to prevent mental disorders. It was about $26 \%$ respondents who choosed seeking for social support. The other $(24,62 \%)$ thought that consult to professional helper was the right choice. The rest respondent stated increased religious activities $(10 \%)$, self management $(8,46 \%)$, recreation $(3,08 \%)$, to be patient $(2,31 \%)$ and engaging healty life style.

There was $6,15 \%$ respondents who did not understand how to prevent of mental disorders. They left the questions without any answer.

\section{DISCUSSION}

The aim of this study is to investigate the knowledge and belief about mental disorder in adolescents. On the first question that pertained to describe their knowledge about mental disorders, the result showed that they could not describe it comprehensively. As indicated on table 2, they tend to describe mental disorders only on one feature such as, problem with emotion, problem with behavior or problem with the way of thinking. It was narrowing the formal definition of mental disorders. Meanwhile, the concept of mental disorders according to WHO (2004) is more comprehensive including biology, psychology, and social aspects.

Some of the respondents could not differentiate between mental disorders and psychological problems. Stress, lack of confidence or lack of problem solving skill were stated as mental disorders. As a consequence of this wrong judgement, youth felt more stress even their conditions were not very serious.

There are many factors as contributory to the onset of mental disorders. Unfortunately, the respondents only knew a single factor such as psychological stressors or social, biologic, economic, and religious factors. Most of them easily identified the others factors than biologic factor. This finding supports to the result of study held by Hugo, Boshoff, Traot et all (2003) that most respondents considered the disorders as being stress-related rather having medical etiology. Consequently, seeking help from the surrounding was rate higher than searching medical help.

Belief in the sources of mental disorders has an implication on the choice of prevention and treatment of this mental disorders. It was not supprising that on the question of "what can we do to prevent mental disorders ?", the respondents stated that they need social support from significant persons in their circumstances, such as family and friends. Moreover, in the last question pertained to help people with mental disorders, they also belived that giving social support was the primary help for those people.

A few respondents believed that lack of religious fate has a role to play in mental disorders. However, none of them believed mental disorders tobe caused by an evil spirits or witchcraft which is a common phenomenon in non western countries and may influence the type of treatment in sought (Jorm, et all 1997). In Malaysia, it was found that psychiatric patient who believed in supernatural causes were more likely to make use of traditional healer and were less willing to comply with medication (Razali, Khan \& Hasanah, 1996).

In term of symptoms recognition, most of respondents were more familiar with behavioral symptoms than emotional, or cognitive symptoms. This means they need a symptoms recognition education since proper recognition of mental illness symptoms is another important determinant of treatment seeking behavior since the other symptoms were as important as the behavioral symptoms.

In term of prevention and helping behavioryor mental disorders, social support became the most important aspect that must be provided in schools. Teachers and student must be able to seek and provide social support in order to prevent and treatment of mental disorders. Letvak (2002), found that social support have direct effect on wellbeing of individuals and families. Meanwhile, students with lower quality of social support were more likely to have mental health problems (Hefner, 2009).

As lack of religousity was considered as one of source of mental disorders, programs for prevention and helping behavior for mental disorders are also need to include religious healers. Based on the research conducted by Levin (2010), there was empirical evidence that supports a generally protective effect of religious in volvementfor mental illnes and psychological distress (Levin, 2010)

There are several misundertanding about prevention and helping behavior for mental disorders. First, one respondent said that "dipasung" was the way that suitable for the person with mental disorder. "Dipasung" means restricted the patients to stay at home all the day or isolated them from the public, or neglected them. This represented the wrong 
socialization from the community. Unfortunately, the National Health Survey (2013) conducted by ministry of health found that $14.3 \%$ of family's of mental disorders patients practiced pasung. This indicated the need of socializing correct treatment of person with mental disorders to the public, including adolescents. Second, there were $9,23 \%$ respondents who described some symptoms as the causes of mental disorders, such as never smile and daydreaming all the time. No one stated that many factors influenced mental disorders. Finally, some of them missuderstood of helping behavior for people with mental illness. In their opinion, being happy or doing therapy could be described as helping behavior.

Based on this findings above, the adolescents were supposed to have low mental health literacy. These findings are consistent with previous report that stated the mental health literacy of adolescents and young adults is not high( Wright et all, 2005). Poorer mental health literacy amongst adolescence may due to a number of factors. There was no education programs delivered in schools for students systematically. Current mental health literacy campaigns may be held incidently. Teachers who were significant figure in schools for educate their students still had low mental health litaeracy too (Asyanti \& Karyani, 20017).

As a consequences, It is important to conduct mental health literacy programs and campaigns in schools. As illiterate mental disorders had serious impacts. Seedat, Stein, Berk et all (2002) who doing study in South Africa, that formed part of an international survey of mental health advocacy group member suffering from mood and anxiety disorders, revealed that most participants waited $3-5$ years before seeking help, and stated reasons such as not knowing where to go, wanting to handle the problem on their own, fear of embarrassment, and fear of medication, as being contributory.Kitchenner and Jorm (2002) found that individuals that took a part on their mental health first aids course showed improvement in recognizing disorders, and their views about treatment of disorders became more in line with the professionals in the mental health fields. In addition, the course reduced their stigma attached to mental disorders, increased their feeling in providing help and increased the help provided to others. Lam (2014) added that adequate level of mental helath literacy is represented when both aspect are satisfied indicating that not only the individual acquire an understanding of problems, but also having a positive attitude toward help seeking action.Rickwood, Deane, Wilson and Ciarroci (2005) stated that insufficient knowledge to identify mental health symptoms and to access treatment impact on poor seek help action on adolescents.

The ristriction of this study was on the respondent which were involved. Thus impact on the generalization of the result. In this study, the questionaire reveal general understanding of mental disorders and not stated spesific issues such as depression, skizofrenia, manic depresif etc. Response of the respondents became very variative.

\section{CONCLUSION}

This study aims to investigate the knowledge of mental heakth literacy among adolescence. The result indicate tahat adolescence did't have adequate knowledge of mental disorders campaing on mental health literacy on themin order to enhace their knowledge sgould be considered.

\section{REFERENCES}

American Psychiatric Association. (2013). DSM-5. Washington DC : American Psychiatric Publishing

Asyanti, S \& Karyani (2017). Community Research Report. Muhannadiyah Malang

Atkins, M., Hoagwood, K., Kutash, K., Seidman, E. (2010). Toward the Integration and Mental Health in School. Adm Policy Mental Health. 37 (1-2), 40-47

Bhatia,S. (2007). Childhood and Adolescent Depression. American family physician. 75 (1) 73

Burn, J.R. and Rapee, R.M. (2006). Adolescence Mental Health Literacy : Young people's knowledge of depression and help seeking. Journal of adolescence, 26 , 225-239.

DOI 10.1016/j.adolescence.2005.05.004

Hefner, J. (2009). Social Support and mental health Among College Students. American Journal of orthopsychiatry, 79 (4) 491-499

Hugo, C.J., Boshoff, D.E.L., Traot, A. Zungu-Dirwayi, N, Stein. D.J. (2003). Community attitude toward and knowledge of mental illness in south africa. Social Psychiatry Psychiatr Epidemio, 38, 715-719

Jorm,A.F., Korten, A.E., Jacomb, P.A., Chistensen, H., Rodgers, B, Pollitt, P. (1997) Mental Health Literacy : A survey of public ability to recognize mental disorders and their belief about the effectiveness of treatment. Medical journal of Australia. 166, 182-186

Kesler, R.C., Bergland, P., Demler, O., Jin, R.,Merikangas, K.R. (2005). Life time prevalence and age of onset distributions of DSM-IV disorders in the national commorbidity survey replication. Arc Gen Psychiatry. 62 (6), 593-602

Kickbusch, I.S. (2001). Health Literacy : Adressing the health and education devide. Health Promotion International 2001. 16, 289-297

Kitchener, B, A. \& Jorm, A,F. (2002). Mental health First Aid Traning for the Public: Evaluation of Effect, Attitudes and Hekping Behavior. Bio Med Central. Psychiatry, 2, 10. Doi; 10.1186/1471-244X-2-10.

Lam, L.T. (2014). Mental Health Literacy and mental Health Status in Adolescents : A population based survey. Child and Adolescent Psychiatry and mental Health. $8 ; \quad 26 ; \quad$ pg $2-8$, http://www.capmh.com/content/8/1/26

Letvak, S. (2002). The Importance of Social Support for mental health. Issues in Mental Helath Nursing. 23(2), 249-261

Levin, J. (2010) Religion and Mental Helath : Theory and research. International Journal of Psychoanalitic Studies. Published online in Wiley Interscience (www.interscience.wiley.com) DOI10.1002/aps.240

Ministry of Heatlh. (2013). National Health Research. www.depkes.go.id

Oktavianus, K \&Ramdhani, N. (2012). Mental Health Literacy through website and chatbot to increase adolescents' knowledge about depression. Thesis. Faculty of Psychology, GadjahMada University.

Razali, S.M., Khan, D.A., Hasanah, C.L. (1996). Belief in supranatural causes of mental illness among malay 
patients : impact on treatment. Acta Psychiatic Scand. 94, 229-233

Rickwood, D., Deane, F.P., Wilson, C.J., \&Ciarrochi. (2005). Young people's help seeking for mental problems. Australian e-journal for Advancement of mental Health (suplement), 4, 1-34. Retrieved from www.auseinet.com/journal/vol4iss3suppl/rickwood. pdf

Seedat, S. Stein, D.J., Berk, M., Wilson, Z. (2002). Barriers to treatment among members of a mental healthadvocacy group in south Africa. Soc Psychiatiy psychiatr epidemio. 37, 483-487

World Health Organisation (2004). Promoting Mental Health : Concept, emerging evidence and practice. http://www.who.int

Wyn,J., Cahill, H., Holdsworth, R., Rowling, L., Carson, S.(2000). MindMatters : A Whole School Approach promoting Mental Health and Wellbeing. Australian New Zealand Journal of Psychiatric, 34, 594-601

Wright, A., Haris, M.G., Wiggers, J.H., Jorm, A.F., Cotton, S.M, Harrigan, S.M., Hurworth, R.R., McGorry, P.D. (2005). Recognition of depression and psychosis by young Australians and their beliefs about treatment. 